\title{
Dexmedetomidine alleviates cerebral ischemia-induced short-term memory impairment by inhibiting the expression of apoptosis-related molecules in the hippocampus of gerbils
}

\author{
IN-YOUNG CHOI ${ }^{1}$, LAKKYONG HWANG ${ }^{1}$, JUN-JANG JIN ${ }^{1}$, IL-GYU KO ${ }^{1}$, SUNG-EUN KIM ${ }^{1}$, MAL-SOON SHIN ${ }^{1}$, \\ KEY-MOON SHIN ${ }^{1}$, CHANG-JU KIM ${ }^{1}$, SUNG-WOOK PARK ${ }^{2}$, JIN-HEE HAN ${ }^{2}$ and JAE-WOO YI ${ }^{3}$ \\ ${ }^{1}$ Department of Physiology, Kyung Hee University College of Medicine, Seoul 130-701; \\ ${ }^{2}$ Department of Anesthesiology and Pain Medicine, Kyung Hee Medical Center, Kyung Hee University College of Medicine, \\ Seoul 130-872; ${ }^{3}$ Department of Anesthesiology and Pain Medicine, Kangdong Kyung Hee Hospital, \\ Kyung Hee University College of Medicine, Seoul 134-727, Republic of Korea
}

Received August 13, 2015; Accepted November 4, 2016

DOI: $10.3892 / \mathrm{etm} .2016 .3956$

\begin{abstract}
Cerebral ischemia results from cerebrovascular occlusion, which leads to neuronal cell death and eventually causes neurological impairments. Dexmedetomidine is a potent and highly selective $\alpha_{2}$-adrenoreceptor agonist with actions such as sedation, anxiolysis, analgesia and anesthetic-sparing effects. We investigated the effect of dexmedetomidine on apoptosis in the hippocampus after transient global ischemia in gerbils. Transient global ischemia was induced by ligation of both common carotid arteries. Dexmedetomidine was administrated intraperitoneally at three respective doses $(0.1$, 1 and $10 \mu \mathrm{g} / \mathrm{kg}$ ) once per day for 14 consecutive days beginning a day after surgery. Short-term memory was assessed by use of a step-down avoidance task. Apoptosis was evaluated by terminal deoxynucleotidyl transferase-mediated deoxyuridine triphosphate nick end labeling assay, immunohistochemistry for caspase-3, and western blot analysis of Bcl-2-associated X protein, $\mathrm{B}$-cell lymphoma 2, Bid, cytochrome $c$, apoptotic protease activating factor- 1 and caspase- 9 in the hippocampus. Induction of global ischemia deteriorated short-term memory by enhancing the expression of apoptosis-related molecules in the hippocampus. Treatment with dexmedetomidine suppressed the expression of apoptosis-related molecules under ischemic conditions, resulting in short-term memory improvement. Under normal conditions, dexmedetomidine exerted no significant effect on apoptosis in the hippocampus. The present results suggest that the $\alpha_{2}$-adrenoceptor agonist
\end{abstract}

Correspondence to: Professor Jae-Woo Yi, Department of Anesthesiology and Pain Medicine, Kangdong Kyung Hee Hospital, Kyung Hee University College of Medicine, 892 Dongnam-ro, Seoul 134-727, Republic of Korea

E-mail: mdyjwchk@khu.ac.kr

Key words: transient global ischemia, dexmedetomidine, $\alpha_{2}$-adrenergic receptor, apoptosis, short-term memory, gerbils dexmedetomidine may be a useful therapeutic agent for the treatment of ischemic brain diseases.

\section{Introduction}

Ischemic brain injury occurs when cerebral blood flow is reduced to a low level, which results in deprivation of oxygen and glucose in brain tissues. These events activate multiple processes that lead to cell death signaling, including excitotoxicity, oxidative stress and caspase activation (1-3). The hippocampus is vulnerable to temporary imperforation of blood flow, and impairment in learning ability and memory function is a remarkable behavioral consequence of transient global ischemia $(4,5)$.

Apoptosis is the major pathway of cell death following cerebral ischemic injury (6). It is a process of programmed cell death triggered by a variety of stimuli, and it is a part of common mechanisms in tissue remodeling, cell replacement and the removal of damaged cells (7). Excessive or inappropriate apoptosis, however, is involved in several types of neurodegenerative disorders, including stroke $(4,8)$. Apoptotic cell death can be assessed using terminal deoxynucleotidyl transferase-mediated deoxyuridine triphosphate nick end labeling staining, which detects DNA fragmentation (9). In addition, apoptosis can also be assessed by examining the expression of proteins involved in the regulation of apoptosis. For example, the caspases, a family of 14 cysteine proteases, are crucial players in apoptotic cell death both as initiators (caspase-2, -8, -9 and -10) and as executioners (caspase-3, -6 and -7) (10). Furthermore, activation of caspase-3 is an important feature of apoptosis following ischemic brain insults (11). The cell-damaging mechanisms that are activated by ischemia are countered by cell-survival mechanisms that include upregulation of the anti-apoptotic molecules, B-cell lymphoma 2 (Bcl-2) and $\mathrm{Bcl}-2_{\mathrm{XL}}$ (12). In addition, the anti-apoptotic protein $\mathrm{Bcl}-2$ suppresses apoptosis by preventing the release of cytochrome $c$ (13) whereas the pro-apoptotic protein Bcl-2associated $\mathrm{X}$ protein (Bax) promotes apoptosis by enhancing cytochrome $c$ release (14). Cytosolic cytochrome $c$ binds to 
apoptotic protease activating factor-1 (Apaf-1), which then forms the apoptosome and leads to the subsequent activation of caspase-9. Caspase-9 is important in neuronal cell death following ischemia (15).

The $\alpha_{2}$-adrenoreceptor agonist dexmedetomidine is a sedative and analgesic agent used for postoperative intensive care sedation, which reduces the requirement for opioid analgesia (16). It stimulates the pre-synaptic $\alpha_{2}$-adrenoceptors, which subsequently inhibit the release of noradrenaline at the sympathetic synapses and reduce the surgical stress response and central sympathetic outflow (17). Dexmedetomidine has been suggested to have neuroprotective effects by stimulating $\alpha_{2}$-adrenoreceptors $(18,19)$. In addition, it has also been demonstrated to improve histomorphological and neurological outcomes following cerebral ischemia (20). Furthermore, the dexmedetomidine-activated signaling pathway was shown to prevent cellular apoptosis when neuronal cells were subjected to ischemic insults $(21,22)$.

In the present study, the effect of dexmedetomidine on short-term memory was investigated following transient global ischemia in gerbils. In addition, the modulatory effect of dexmedetomidine on the expression of apoptosis-regulating proteins in the hippocampus was evaluated.

\section{Materials and methods}

Experimental animals and treatments. A total of 50 adult male Mongolian gerbils (12 weeks of age; Orient Bio Co., Seoul, Korea) were used for this experiment. The experimental procedures were performed in accordance with the Animal Care Guidelines of the National Institutes of Health and the Korean Academy of Medical Sciences, and the study was approved by the Kyung Hee University Institutional Animal Care and Use Committee (Seoul, Korea). Gerbils were housed under controlled temperature $\left(23 \pm 2^{\circ} \mathrm{C}\right)$ and lighting (08:00 to $20: 00 \mathrm{~h}$ ) conditions with food and water made available ad libitum.

Gerbils were randomly divided into five groups $(n=10$ per group): Sham-operated, ischemia-induction, ischemia-induction and $0.1 \mu \mathrm{g} / \mathrm{kg}$ dexmedetomidine-treated, ischemia-induction and $1 \mu \mathrm{g} / \mathrm{kg}$ dexmedetomidine-treated and the ischemia-induction and $10 \mu \mathrm{g} / \mathrm{kg}$ dexmedetomidine-treated groups. Dexmedetomidine was procured from Hospira, Inc. (Rocky Mount, NC, USA). The animals in the dexmedetomidine-treated groups received the respective dose of dexmedetomidine intraperitoneally, once per day for 14 consecutive days, starting 1 day after surgery. In addition, the animals in the Sham-operated group received an equivalent dose of saline intraperitoneally, once per day for the same duration.

Induction of transient global ischemia. Transient global ischemia was induced according to a previously described surgical procedure (4). Gerbils were anesthetized with Zoletil $50^{\circledR}$ [10 mg/kg, intraperitoneally (i.p.); Virbac Laboratories, Carros, France]. Following bilateral neck incisions, both common carotid arteries were exposed and occluded with aneurysm clips for $5 \mathrm{~min}$. The clips were then removed to restore cerebral blood flow. The body and rectal temperature was maintained at $36 \pm 0.5^{\circ} \mathrm{C}$ during surgery using a homeo- thermic blanket control unit (Harvard Apparatus, Holliston, MA, USA) that enveloped the body and the head. Following recovery, the animals were monitored for an additional $2 \mathrm{~h}$ to prevent hypothermia. The animals in the Sham-operated group were treated identically except that the common carotid arteries were not occluded after the neck incisions.

Step-down avoidance task. Latency in the step-down avoidance task was determined to evaluate short-term memory according to a previously described method $(8,23)$. Gerbils were trained in a step-down avoidance task 15 days after the induction of ischemia. At $1 \mathrm{~h}$ after training, the latency in each group was determined. The gerbil was then placed on a $7 \times 25-\mathrm{cm}$ platform that was $2.5 \mathrm{~cm}$ in height, and the platform faced a $45 \times 25-\mathrm{cm}$ grid of parallel stainless steel bars, $0.1 \mathrm{~cm}$ in caliber and spaced $1 \mathrm{~cm}$ apart. In the training session, the animal received a $0.3 \mathrm{~mA}$ scramble foot shock for $2 \mathrm{sec}$ immediately upon stepping down. The time that elapsed until the gerbil stepped down and placed all four paws on the grid was defined as the latency period. A latency time over $180 \mathrm{sec}$ was counted as $180 \mathrm{sec}$.

Tissue preparation. Gerbils were sacrificed immediately after determining the latency of the step-down avoidance task. The gerbils were anesthetized with Zoletil $50^{\circledR}(10 \mathrm{mg} / \mathrm{kg}$, i.p.), transcardially perfused with $50 \mathrm{mM}$ phosphate-buffered saline and fixed with a freshly prepared solution consisting of $4 \%$ paraformaldehyde in $100 \mathrm{mM}$ phosphate buffer (PB, $\mathrm{pH}$ 7.4). Brains were dissected and stored overnight in the same fixative and were then transferred to $30 \%$ sucrose for cryoprotection. For immunohistochemistry, 40- $\mu \mathrm{m}$ slices were coronally sectioned by the use of a cryostat (Leica Biosystems, Nussloch, Germany). In total ten slice sections in the hippocampus were collected on average from each gerbil. The sections ranging between 2.5 and $2.7 \mathrm{~mm}$ posterior from the bregma were used for immunohistochemistry.

Terminal deoxynucleotidyl transferase-mediated deoxyuridine triphosphate nick end labeling (TUNEL) staining. In order to visualize DNA fragmentation, a marker of apoptosis, TUNEL staining was performed using an In Situ Cell Death Detection kit ${ }^{\circledR}$ (Roche Diagnostics GmbH, Mannheim, Germany) according to the manufacturer's instructions $(4,24)$. The sections were post-fixed in ethanol-acetic acid $(2: 1)$, rinsed, then incubated with proteinase $\mathrm{K}(100 \mu \mathrm{g} / \mathrm{ml})$. They were then rinsed, incubated in $3 \% \mathrm{H}_{2} \mathrm{O}_{2}$, permeabilized with $0.5 \%$ Triton $\mathrm{X}-100$, rinsed again and incubated in the TUNEL reaction mixture. Finally, the sections were rinsed once more and visualized using Converter-POD with $0.03 \%$ 3,3'-diaminobenzidine (DAB). Mayer's hematoxylin (Dako, Glostrup, Denmark) was used as a counterstain, and the sections were mounted onto gelatin-coated slides. The slides were then air-dried overnight at room temperature, and coverslips were mounted using Permount ${ }^{\circledR}$ (Thermo Fisher Scientific, Inc., Waltham, MA, USA).

Caspase-3 immunohistochemistry. In order to visualize the caspase-3 expression, caspase- 3 immunohistochemistry was performed as previously described $(4,24)$. The sections were selected from each brain and incubated overnight with 
caspase-3 antibody (cat. no. SC-7272; 1:500; Santa Cruz Biotechnology, Inc., Dallas, TX, USA), then with biotinylated mouse secondary antibody (cat. no. BA-2000; 1:200; Vector Laboratories,Inc., Burlingame,CA,USA) for $1 \mathrm{~h}$. The secondary antibody was amplified using a Vector Elite ABC kit ${ }^{\circledR}$ (1:100; Vector Laboratories, Inc.). Antibody-biotin-avidin-peroxidase complexes were visualized using $0.03 \%$ DAB, and the sections were mounted onto gelatin-coated slides. The slides were air-dried overnight at room temperature, and coverslips were mounted using Permount ${ }^{\circledR}$ (Thermo Fisher Scientific, Inc.).

Western blot analysis. Western blotting was performed as previously described $(8,23)$. The hippocampal tissues were collected and then frozen immediately at $-70^{\circ} \mathrm{C}$. The hippocampal tissues were homogenized on ice and lysed in a lysis buffer containing $50 \mathrm{mM}$ HEPES (pH 7.5), $150 \mathrm{mM} \mathrm{NaCl}$, $10 \%$ glycerol, $1 \%$ Triton X-100, $1 \mathrm{mM}$ phenylmethylsulfonyl fluoride, $1 \mathrm{mM}$ EGTA, $1.5 \mathrm{mM} \mathrm{MgCl}_{2} \times 6 \mathrm{H}_{2} \mathrm{O}, 1 \mathrm{mM}$ sodium orthovanadate and $100 \mathrm{mM}$ sodium fluoride. The protein content was measured using a colorimetric protein assay kit (cat. no. 5000002; Bio-Rad Laboratories, Inc., Hercules, CA, USA). For the detection of cytochrome $c$, tissues were fractionated into the cytosol using the mitochondrial fraction kit (cat. no. 40015; Active Motif, Carlsbad, CA, USA) according to the manufacturer's instructions. In total, $30 \mu \mathrm{g}$ protein was separated on $12 \%$ SDS-polyacrylamide gels and transferred onto a nitrocellulose membrane. The membranes were incubated with $5 \%$ skim milk in Tris-buffered saline containing $0.1 \%$ Tween-20 (TBST) and then incubated for $1 \mathrm{~h}$ at room temperature. The membrane was washed with TBST for $10 \mathrm{~min}, 3$ times at room temperature. Mouse $\beta$-actin antibody (cat. no. SC-47778; 1:1,000), mouse Bax antibody (cat. no. SC-7480; 1:1,000), mouse Bcl-2 antibody (cat. no. SC-7382; 1:1,000), goat Apaf-1 antibody (cat. no. SC-7232 1:1,000), rabbit Bid antibody (cat. no. SC-11423; 1:1,000), rabbit caspase-9 antibody (cat. no. SC-7885; 1:1,000) and rabbit cytochrome $c$ antibody (cat. no. SC-7159; 1:1,000) all from Santa Cruz Biotechnology, Inc. were used at $4{ }^{\circ} \mathrm{C}$ ovenight. Horseradish peroxidase-conjugated anti-rabbit antibody for Bid, caspase-9 and cytochrome $c$ (cat. no. PI-1000; 1:2,000; Vector Laboratories, Inc.); horseradish peroxidase-conjugated anti-mouse antibody for $\beta$-actin, Bax and Bcl-2 (cat. no. PI-2000; 1:2,000; Vector Laboratories, Inc.); and horseradish peroxidase-conjugated anti-goat antibody for Apaf-1 (cat. no. PI-9500; 1:2,000; Vector Laboratories, Inc.) were used as the secondary antibodies for $1 \mathrm{~h}$ at room temperature.

The experiments were performed in normal laboratory conditions and at room temperature, except for the transferred membranes. Transferred membranes were performed at $4^{\circ} \mathrm{C}$ with a cold pack and pre-chilled buffer. The bands were detected using an enhanced chemiluminescence detection kit (cat. no. 170-5061; Santa Cruz Biotechnology, Inc.). In order to compare the relative expression of proteins, the detected bands were calculated densitometrically using Molecular Analyst, version 1.4.1 (Bio-Rad Laboratories, Inc.,).

Data analysis. The numbers of TUNEL-positive and caspase-3-positive cells in the selected hippocampal areas (CA1, CA2-3 and dentate gyrus) were counted hemilaterally under an Olympus-BX51 light microscope (Olympus
Corporation, Tokyo, Japan) and were expressed as the number of cells per $\mathrm{mm}^{2}$ in the selected hippocampal areas. The areas of hippocampal CA1, CA2-3 and dentate gyrus were measured using the Image-Pro ${ }^{\circledR}$ Plus computer-assisted image analysis system version 4.5.1.22 (Media Cybernetics Inc., Rockville, $\mathrm{MD}$, USA). In order to confirm the expression of Bcl-2, Bax, Bid, cytochrome $c$, Apaf-1 and caspase-9, the detected bands were calculated densitometrically using the Image-Pro Plus image analysis system (Media Cybernetics Inc.). Statistical analysis was performed using one-way analysis of variance followed by Duncan's post-hoc test, and the results were expressed as the mean \pm standard error of the mean. $\mathrm{P}<0.05$ was used to indicate a statistically significant difference.

\section{Results}

Effect of dexmedetomidine on short-term memory in the step-down avoidance task. A step-down avoidance task was performed in order to evaluate the effect of dexmedetomidine on short-term memory. The latencies in the step-down avoidance task are presented in Fig. 1. Latency was $58.92 \pm 8.83 \mathrm{sec}$ in the Sham-operated, 20.08 $\pm 10.06 \mathrm{sec}$ in the ischemia-induction, $28.7 \pm 9.58 \mathrm{sec}$ in the ischemia-induction and $0.1 \mu \mathrm{g} / \mathrm{kg}$ dexmedetomidine-treated, 36.5 $\pm 7.92 \mathrm{sec}$ in the ischemia-induction and $1 \mu \mathrm{g} / \mathrm{kg}$ dexmedetomidine-treated and $34.0 \pm 7.81 \mathrm{sec}$ in the ischemia-induction and $10 \mu \mathrm{g} / \mathrm{kg}$ dexmedetomidine-treated groups.

Induction of ischemia disturbed short-term memory $(\mathrm{P}<0.05)$, whereas dexmedetomidine treatment with 1 and $10 \mu \mathrm{g} / \mathrm{kg}$ alleviated ischemia-induced short-term memory impairment in gerbils $(\mathrm{P}<0.05)$. In the Sham-operated gerbils, dexmedetomidine treatment exerted no significant effect on short-term memory (Fig. 2).

Effect of dexmedetomidine on the number of TUNEL-positive cells in the hippocampus. Photomicrographs of TUNEL-positive cells in the hippocampus are presented in Fig. 3 (lower). The numbers of TUNEL-positive cells in the CA1, CA2-3 and dentate gyrus regions were $57.30 \pm 7.85,38.28 \pm 2.90$ and $36.67 \pm 5.52 / \mathrm{mm}^{2}$ in the Sham-operated; $1,290.59 \pm 106.45$, $481.59 \pm 58.90$ and $643.21 \pm 91.05 / \mathrm{mm}^{2}$ in the ischemia-induction; $1,103.63 \pm 176.84,486.66 \pm 33.06$ and $580.02 \pm 46.85 / \mathrm{mm}^{2}$ in the ischemia-induction and $0.1 \mu \mathrm{g} / \mathrm{kg}$ dexmedetomidine-treated; $1,077.96 \pm 108.16,465.17 \pm 56.67$ and $372.78 \pm 37.36 / \mathrm{mm}^{2}$ in the ischemia-induction and $1 \mu \mathrm{g} / \mathrm{kg}$ dexmedetomidine-treated; and $864.04 \pm 70.76,329.95 \pm 46.93$ and $357.87 \pm 40.98 / \mathrm{mm}^{2}$ in the ischemia-induction and $10 \mu \mathrm{g} / \mathrm{kg}$ dexmedetomidine-treated groups, respectively.

Induction of ischemia enhanced DNA fragmentation in the hippocampus $(\mathrm{P}<0.05)$, whereas dexmedetomidine treatment suppressed ischemia-induced DNA fragmentation in gerbils $(\mathrm{P}<0.05)$. In the Sham-operated gerbils, dexmedetomidine treatment exerted no significant effect on DNA fragmentation (Fig. 4, left).

Effect of dexmedetomidine on the number of caspase-3-positive cells in the hippocampus. Photomicrographs of caspase-3-positive cells in the hippocampus are represented in Fig. 3 (upper). The numbers of caspase-3-positive cells in the CA1, CA2-3 and dentate gyrus regions were 28.78 \pm 3.56 , 


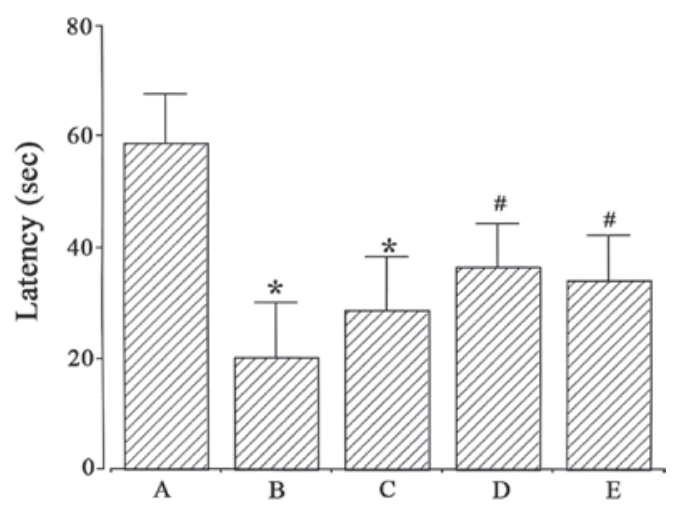

Figure 1. Effect of dexmedetomidine on latency in the step-down avoidance task under ischemic conditions. (A) Sham-operated, (B) ischemia-induction, (C) ischemia-induction and $0.1 \mu \mathrm{g} / \mathrm{kg}$ dexmedetomidine-treated, (D) ischemia-induction and $1 \mu \mathrm{g} / \mathrm{kg}$ dexmedetomidine-treated and (E) ischemia-induction and $10 \mu \mathrm{g} / \mathrm{kg}$ dexmedetomidine-treated groups. Results are expressed as the mean \pm standard error of the mean. ${ }^{*} \mathrm{P}<0.05$ vs. Sham-operated group. ${ }^{~} \mathrm{P}<0.05$ vs. ischemia-induction group.

$47.60 \pm 5.19$ and $34.42 \pm 4.25 / \mathrm{mm}^{2}$ in the Sham-operated; $184.35 \pm 18.81,219.92 \pm 28.75$ and $217.42 \pm 25.93 / \mathrm{mm}^{2}$ in the ischemia-induction; $141.26 \pm 9.92,218.56 \pm 27.45$ and $204.21 \pm 23.68 / \mathrm{mm}^{2}$ in the ischemia-induction and $0.1 \mu \mathrm{g} / \mathrm{kg}$ dexmedetomidine-treated; $146.32 \pm 21.72,220.88 \pm 29.74$ and $193.81 \pm 30.05 / \mathrm{mm}^{2}$ in the ischemia-induction and $1 \mu \mathrm{g} / \mathrm{kg}$ dexmedetomidine-treated, and $108.35 \pm 17.42,141.77 \pm 28.10$ and $116.96 \pm 9.05 / \mathrm{mm}^{2}$ in the ischemia-induction and $10 \mu \mathrm{g} / \mathrm{kg}$ dexmedetomidine-treated groups, respectively.

Induction of ischemia enhanced caspase- 3 expression in the hippocampus $(\mathrm{P}<0.05)$ and dexmedetomidine treatment suppressed ischemia-induced caspase-3 expression in gerbils $(\mathrm{P}<0.05)$. In the Sham-operated gerbils, dexmedetomidine treatment exerted no significant effect on caspase-3 expression (Fig. 4, right).

Effect of dexmedetomidine on the expression of Bcl-2 and Bax proteins. The expression of the anti-apoptotic protein $\mathrm{Bcl}-2$ and the pro-apoptotic protein Bax in the hippocampus was analyzed by western blotting (Fig. 5, left). When the level of Bcl-2 (26-29 kDa) in the Sham-operated group was set at 1.00, the level of Bcl-2 was $0.57 \pm 0.11$ in the ischemia-induction, $1.22 \pm 1.01$ in the ischemia-induction and $0.1 \mu \mathrm{g} / \mathrm{kg}$ dexmedetomidine-treated, $1.92 \pm 1.26$ in the ischemia-induction and $1 \mu \mathrm{g} / \mathrm{kg}$ dexmedetomidine-treated and $2.33 \pm 1.32$ in the ischemia-induction and $10 \mu \mathrm{g} / \mathrm{kg}$ dexmedetomidine-treated groups.

When the level of Bax $(23 \mathrm{kDa})$ in the Sham-operated group was set at 1.00, the level of Bax was $1.90 \pm 0.23$ in the ischemia-induction, $1.39 \pm 0.16$ in the ischemia-induction and $0.1 \mu \mathrm{g} / \mathrm{kg}$ dexmedetomidine-treated, $1.24 \pm 0.15$ in the ischemia-induction and $1 \mu \mathrm{g} / \mathrm{kg}$ dexmedetomidine-treated and $0.84 \pm 0.13$ in the ischemia-induction and $10 \mu \mathrm{g} / \mathrm{kg}$ dexmedetomidine-treated groups.

When the ratio of Bax to Bcl-2 in the Sham-operated group was set at 1.00 , the ratio of $\mathrm{Bax}$ to $\mathrm{Bcl}-2$ was $4.59 \pm 2.58$ in the ischemia-induction group, $2.86 \pm 2.37$ in the ischemia-induction and $0.1 \mu \mathrm{g} / \mathrm{kg}$ dexmedetomidine-treated, $0.62 \pm 0.40$ in the ischemia-induction and $1 \mu \mathrm{g} / \mathrm{kg}$ dexmedetomidine-treated and $0.78 \pm 0.44$ in the ischemia-induction and $10 \mu \mathrm{g} / \mathrm{kg}$ dexmedetomidine-treated groups.

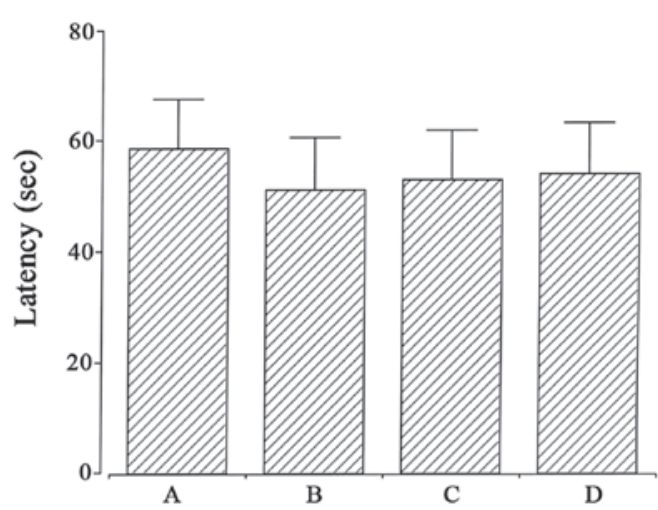

Figure 2. Effect of dexmedetomidine on latency in the step-down avoidance task under normal conditions. (A) Sham-operated, (B) Sham-operated and $0.1 \mu \mathrm{g} / \mathrm{kg}$ dexmedetomidine-treated, (C) Sham-operated and $1 \mu \mathrm{g} / \mathrm{kg}$ dexmedetomidine-treated and the (D) Sham-operated and $10 \mu \mathrm{g} / \mathrm{kg}$ dexmedetomidine-treated groups. Results are expressed as the mean \pm standard error of the mean.

These results revealed that induction of ischemia suppressed Bcl-2 expression $(\mathrm{P}<0.05)$ and enhanced Bax expression in the hippocampus $(\mathrm{P}<0.05)$. Dexmedetomidine treatment enhanced Bcl-2 expression $(\mathrm{P}<0.05)$ and suppressed Bax expression in the ischemic gerbils $(\mathrm{P}<0.05)$. As a result, the ratio of $\mathrm{Bax}$ to $\mathrm{Bcl}-2$ was increased by ischemic insult $(\mathrm{P}<0.05)$, and dexmedetomidine treatment inhibited the ratio of $\mathrm{Bax}$ to $\mathrm{Bcl}-2$ in the ischemic gerbils $(\mathrm{P}<0.05)$. In the Sham-operated gerbils, dexmedetomidine treatment exerted no significant effect on Bcl-2 or Bax expression (Fig. 6, left).

Effect of dexmedetomidine on the expression of Bid protein. The expression of the pro-apoptotic protein Bid in the hippocampus was analyzed by western blotting (Fig. 5 , middle upper). When the level of Bid ( $25 \mathrm{kDa})$ in the Sham-operated group was set at 1.00 , the level of Bid was $1.68 \pm 0.04$ in the ischemia-induction, $1.40 \pm 0.05$ in the ischemia-induction and $0.1 \mu \mathrm{g} / \mathrm{kg}$ dexmedetomidine-treated, $0.95 \pm 0.05$ in the ischemia-induction and $1 \mu \mathrm{g} / \mathrm{kg}$ dexmedetomidine-treated and $0.77 \pm 0.17$ in the ischemia-induction and $10 \mu \mathrm{g} / \mathrm{kg}$ dexmedetomidine-treated groups.

Induction of ischemia enhanced Bid expression in the hippocampus $(\mathrm{P}<0.05)$, and dexmedetomidine treatment decreased Bid expression in the ischemic gerbils $(\mathrm{P}<0.05)$. In the Sham-operated gerbils, dexmedetomidine treatment exerted no significant effect on Bid expression (Fig. 6, middle upper).

Effect of dexmedetomidine on the expression of cytochrome $c$ protein. The expression of cytochrome $c$ in the hippocampal cytosol fraction was analyzed by western blotting (Fig. 5, upper right). When the level of cytochrome $c(15 \mathrm{kDa})$ in the Sham-operated group was set at 1.00, the level of cytochrome $c$ was $1.70 \pm 0.56$ in the ischemia-induction, $1.66 \pm 0.02$ in the ischemia-induction and $0.1 \mu \mathrm{g} / \mathrm{kg}$ dexmedetomidine-treated, $1.33 \pm 0.03$ in the ischemia-induction and $1 \mu \mathrm{g} / \mathrm{kg}$ dexmedetomidine-treated and $0.99 \pm 0.04$ in the ischemia-induction and $10 \mu \mathrm{g} / \mathrm{kg}$ dexmedetomidine-treated groups.

Induction of ischemia enhanced cytochrome $c$ expression in the hippocampus $(\mathrm{P}<0.05)$, and dexmedetomidine treatment 
A

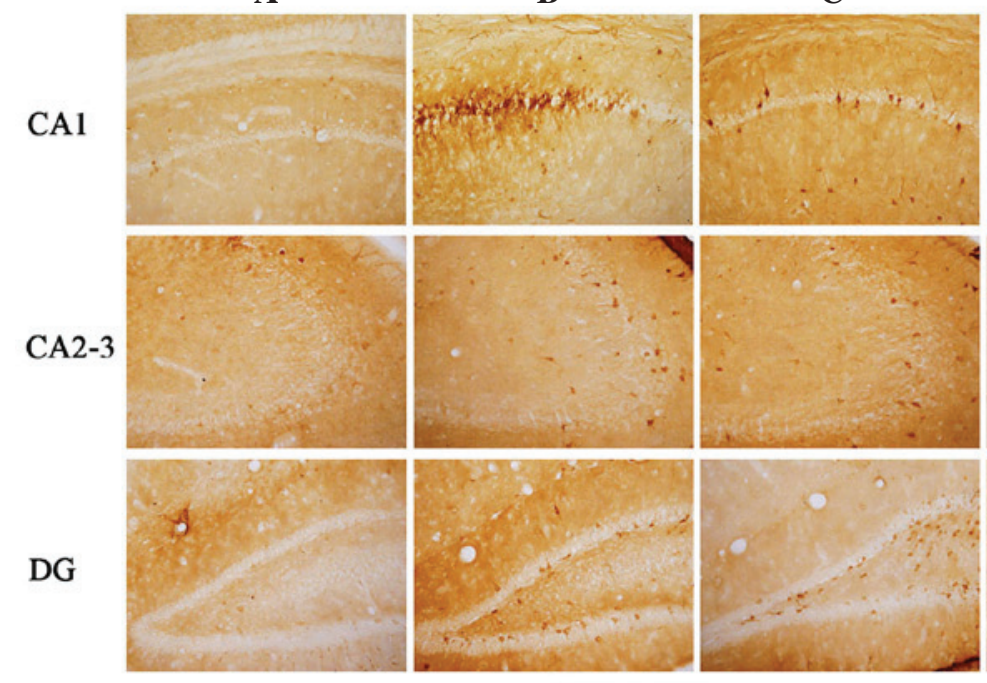

D

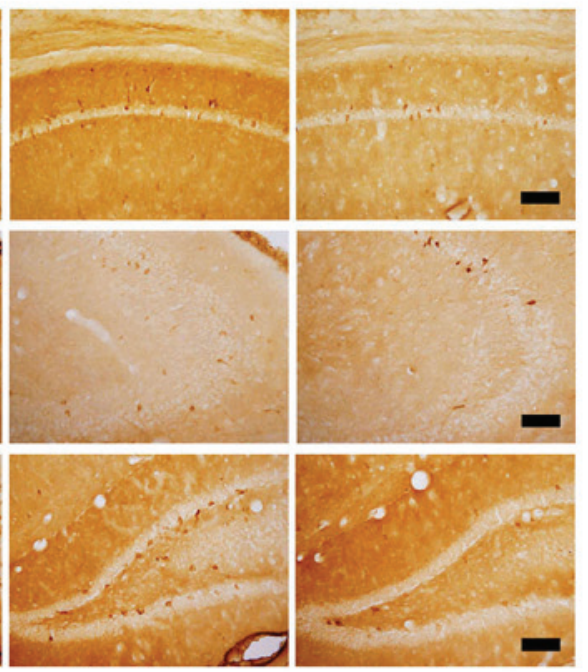

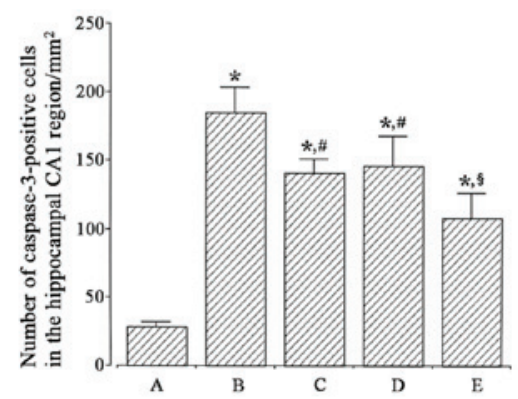
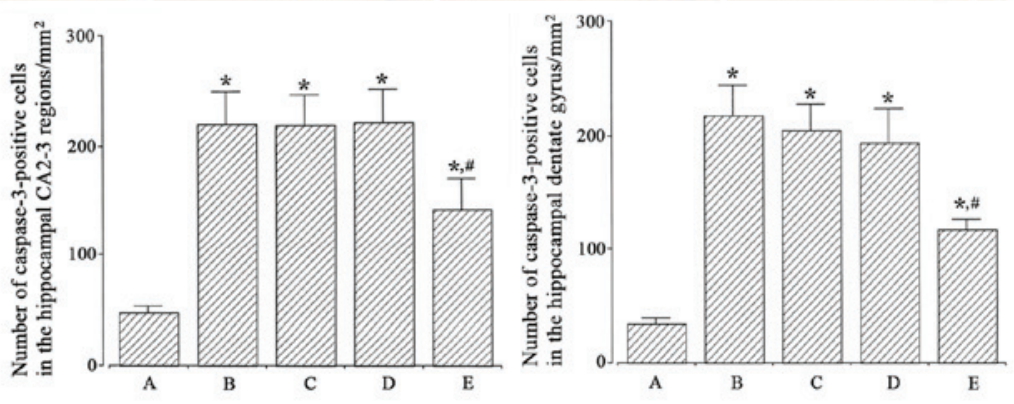

A

B

C

D

$\mathbf{E}$
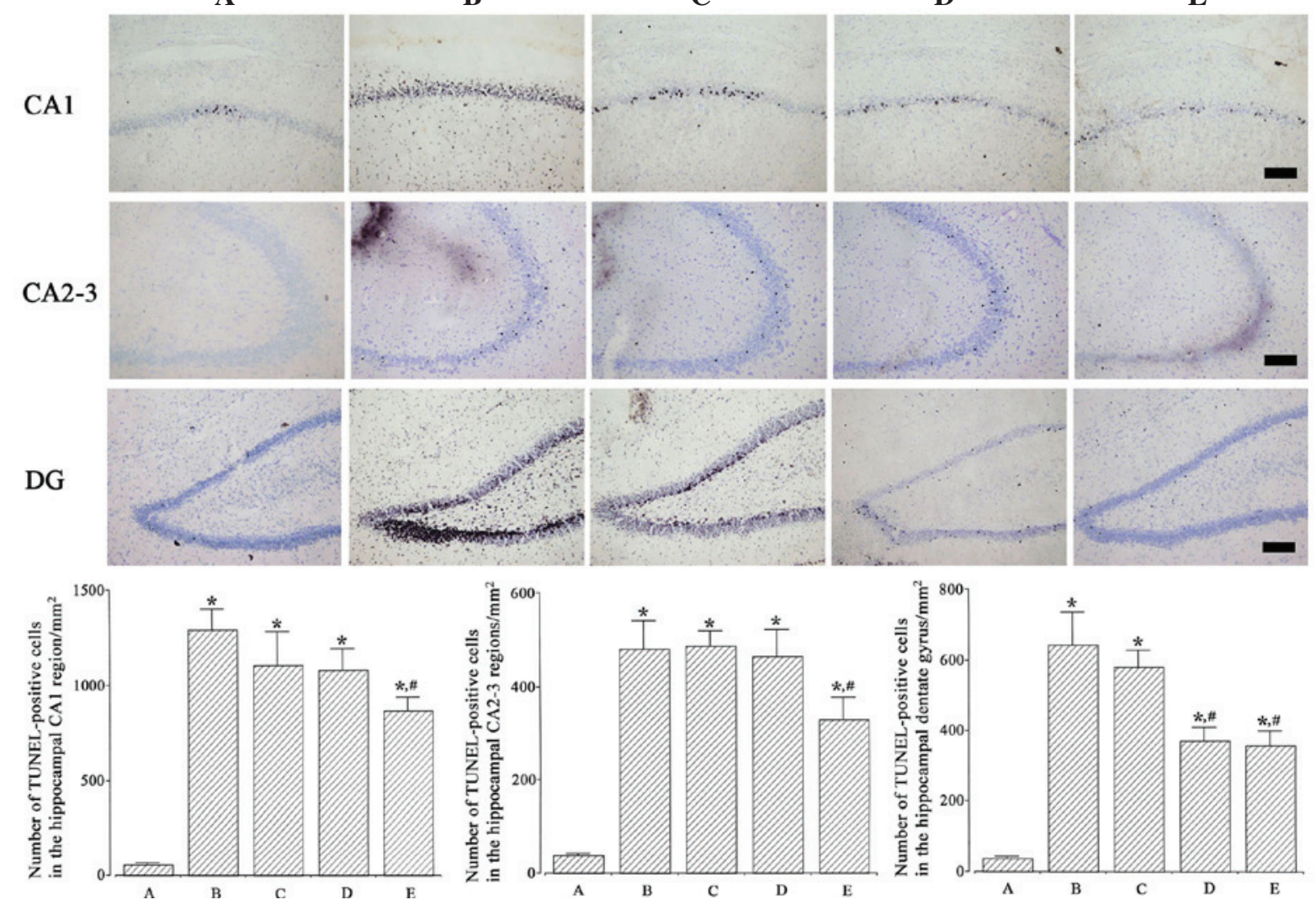

Figure 3. Effects of dexmedetomidine on DNA fragmentation and caspase-3 expression in the hippocampus under ischemic conditions. Upper: TUNEL-positive cells in the hippocampal regions. The scale bar represents $150 \mu \mathrm{m}$. Lower: Caspase-3-positive cells in the hippocampal regions. The scale bar represents $150 \mu \mathrm{m}$. (A) Sham-operated, (B) ischemia-induction, (C) ischemia-induction and $0.1 \mu \mathrm{g} / \mathrm{kg}$ dexmedetomidine-treated, (D) ischemia-induction and $1 \mu \mathrm{g} / \mathrm{kg}$ dexmedetomidine-treated and (E) ischemia-induction and $10 \mu \mathrm{g} / \mathrm{kg}$ dexmedetomidine-treated groups. The results are expressed as the mean \pm standard error of the mean. ${ }^{*} \mathrm{P}<0.05$ vs. Sham-operated group. ${ }^{~} \mathrm{P}<0.05$ vs. ischemia-induction group. CA, Cornu ammonis; DG, dentate gtrus; TUNEL, terminal deoxynucleotidyl transferase-mediated deoxyuridine triphosphate nick end labeling. 

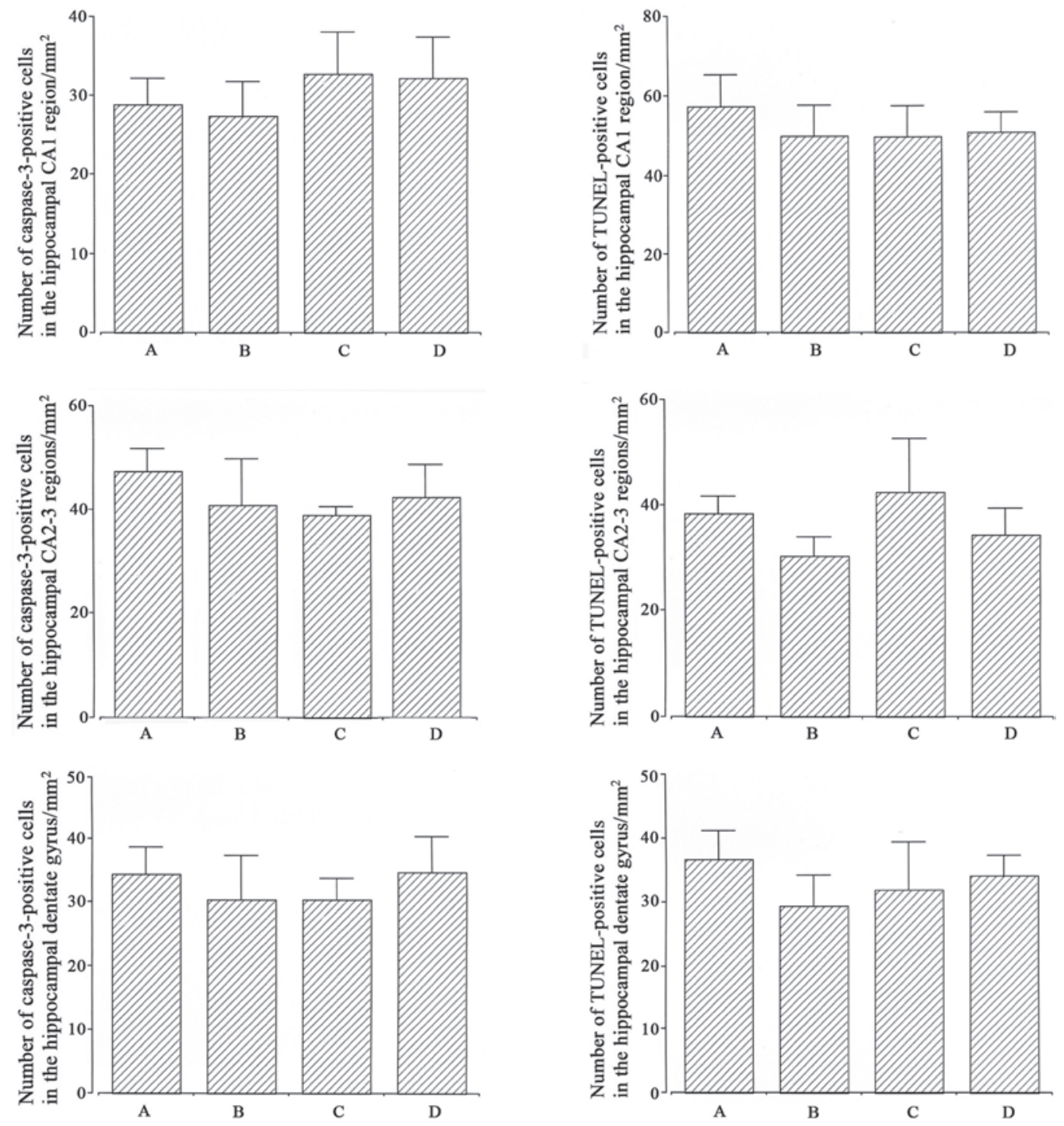

Figure 4. Effects of dexmedetomidine on DNA fragmentation and caspase-3 expression in the hippocampus under normal conditions. (A) Sham-operated, (B) Sham-operated and $0.1 \mu \mathrm{g} / \mathrm{kg}$ dexmedetomidine-treated, (C) Sham-operated and $1 \mu \mathrm{g} / \mathrm{kg}$ dexmedetomidine-treated and (D) Sham-operated and $10 \mu \mathrm{g} / \mathrm{kg}$ dexmedetomidine-treated groups. The results are expressed as the mean \pm standard error of the mean. TUNEL, terminal deoxynucleotidyl transferase-mediated deoxyuridine triphosphate nick end labeling; CA, Cornu ammonis.

decreased cytochrome $c$ expression in the ischemic gerbils $(\mathrm{P}<0.05)$. In the Sham-operated gerbils, dexmedetomidine treatment exerted no significant effect on cytochrome $c$ expression (Fig. 6, upper right).

Effect of dexmedetomidine on the expression of Apaf-1 protein . The expression of the pro-apoptotic protein Apaf-1 in the hippocampus was analyzed by western blotting (Fig. 5, lower middle). When the level of Apaf-1 (130 kDa) in the Sham-operated group was set at 1.00, the level of Apaf-1 was $2.48 \pm 0.12$ in the ischemia-induction, $1.67 \pm 0.11$ in the ischemia-induction and $0.1 \mu \mathrm{g} / \mathrm{kg}$ dexmedetomidine-treated, $1.59 \pm 0.06$ in the ischemia-induction and $1 \mu \mathrm{g} / \mathrm{kg}$ dexmedetomidine-treated and $1.30 \pm 0.08$ in the ischemia-induction and $10 \mu \mathrm{g} / \mathrm{kg}$ dexmedetomidine-treated groups.

Induction of ischemia enhanced Apaf-1 expression in the hippocampus $(\mathrm{P}<0.05)$, and dexmedetomidine treatment decreased Apaf-1 expression in the ischemic gerbils $(\mathrm{P}<0.05)$. In the Sham-operated gerbils, dexmedetomidine treatment exerted no significant effect on Apaf-1 expression (Fig. 6, lower middle).

Effect of dexmedetomidine on the expression of caspase-9 protein. The expression of caspase-9 in the hippocampus was analyzed by western blotting (Fig. 5, right lower). When the expression of caspase-9 $(46 \mathrm{kDa})$ in the Sham-operated group was set at 1.00 , the level of caspase- 9 was $3.58 \pm 0.84$ in the ischemia-induction, $2.86 \pm 0.80$ in the ischemia-induction and $0.1 \mu \mathrm{g} / \mathrm{kg}$ dexmedetomidine-treated, $1.29 \pm 0.24$ in the ischemia-induction and $1 \mu \mathrm{g} / \mathrm{kg}$ dexmedetomidine-treated and $1.23 \pm 0.23$ in the ischemia-induction and $10 \mu \mathrm{g} / \mathrm{kg}$ dexmedetomidine-treated groups.

Induction of ischemia enhanced caspase-9 expression in the hippocampus $(\mathrm{P}<0.05)$, and dexmedetomidine treatment decreased caspase-9 expression in the ischemic gerbils $(\mathrm{P}<0.05)$. In the Sham-operated gerbils, dexmedetomidine treatment exerted no significant effect on caspase-9 expression (Fig. 6, right lower). 

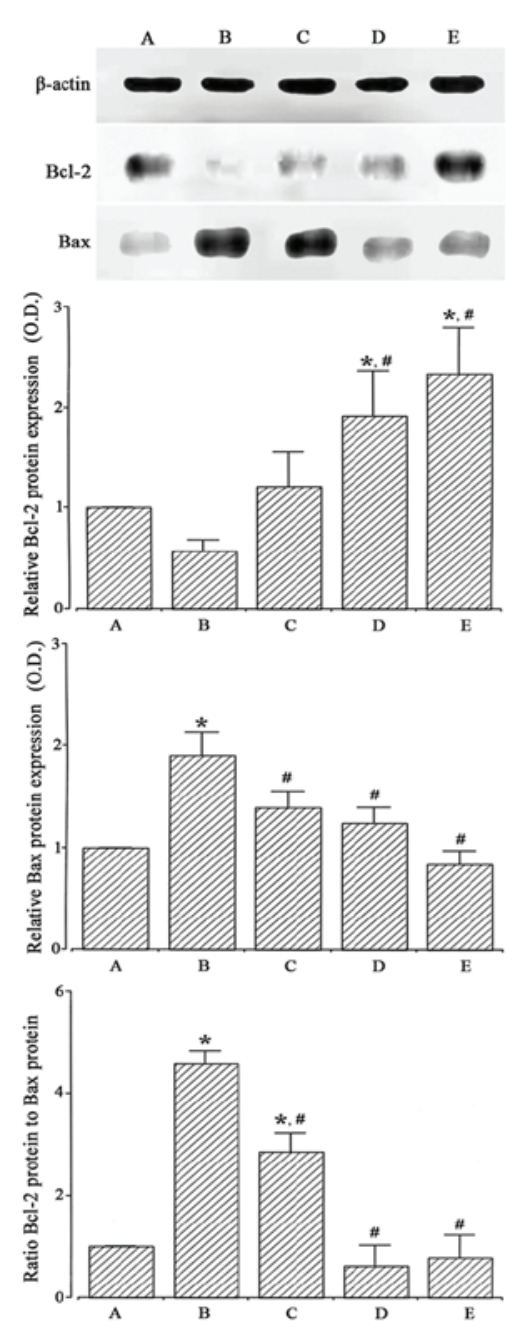
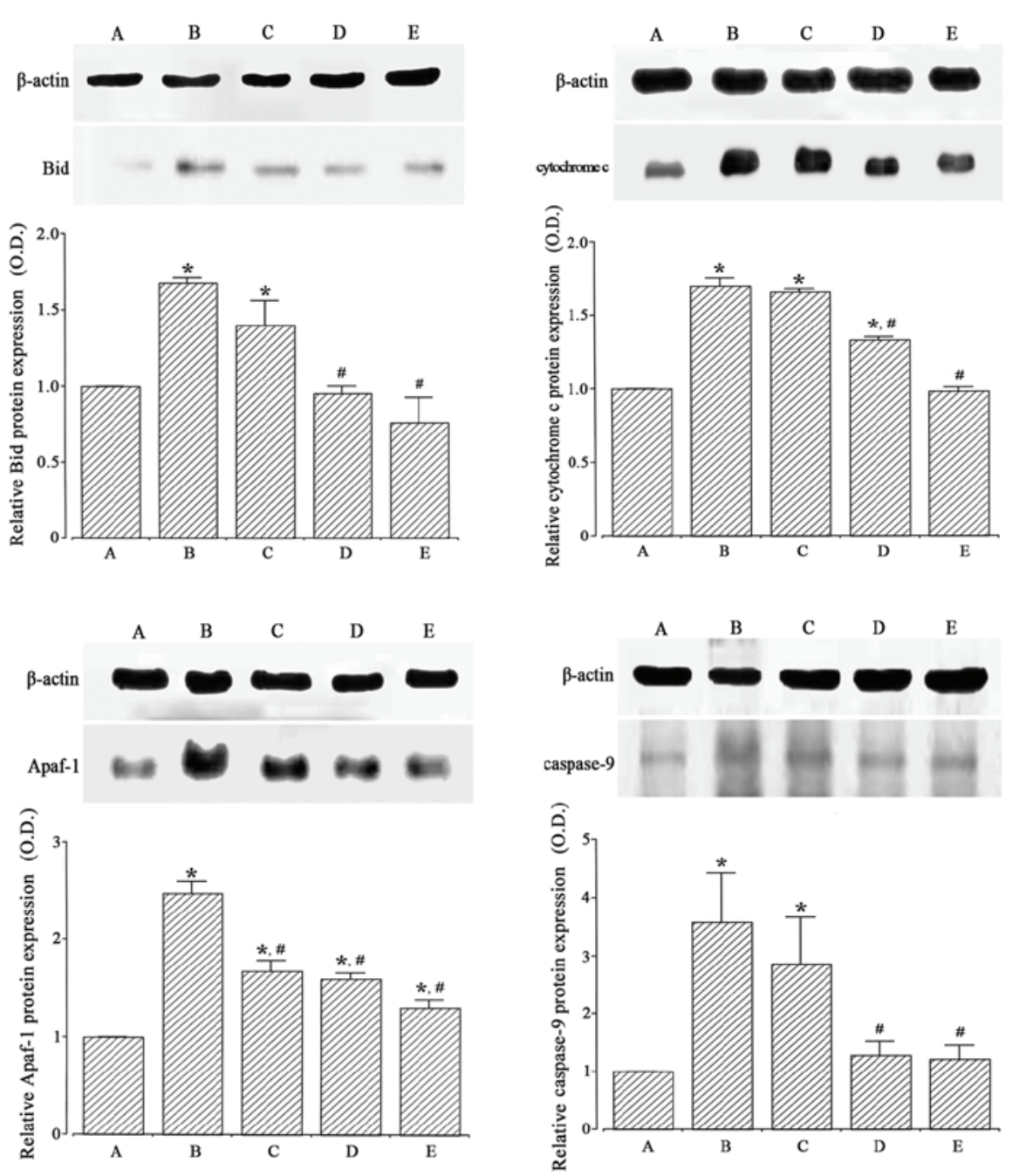

Figure 5. Effects of dexmedetomidine on the expression of apoptotic proteins under ischemic conditions. Actin was used as an internal control (43 kDa). (A) Sham-operated, (B) ischemia-induction, (C) ischemia-induction and $0.1 \mu \mathrm{g} / \mathrm{kg}$ dexmedetomidine-treated, (D) ischemia-induction and $1 \mu \mathrm{g} / \mathrm{kg}$ dexmedetomidine-treated and (E) ischemia-induction and $10 \mu \mathrm{g} / \mathrm{kg}$ dexmedetomidine-treated groups. The results are expressed as the mean \pm standard error of the mean. " $\mathrm{P}<0.05$ compared with the Sham-operated group and ${ }^{\#} \mathrm{P}<0.05$ compared with the ischemia-induction group. Bcl-2, B-cell lymphoma 2; Bax, Bcl-2-associated X protein; O.D, optical density; Apaf-1, apoptotic protease activating factor-1.

\section{Discussion}

Hypoxic ischemia injury induces incapacitation of short-term memory in a step-down avoidance task (4). The decrease of latency in the step-down avoidance task represents memory loss; by contrast, the recovery of latency near to the normal level represents alleviation of memory loss (8). Dexmedetomidine has been revealed to have neuroprotective effects and to facilitate recovery from various brain insults $(18,25,26)$. An ameliorating effect of dexmedetomidine on intracerebral hemorrhage-induced memory impairment was also reported (8). In the present study, the latency period in the step-down avoidance task was shortened by the induction of cerebral ischemia, and dexmedetomidine treatment lengthened the latency in the ischemic gerbils. Thus, the results of the present study revealed that dexmedetomidine alleviated ischemia-induced short-term memory impairment in gerbils.

Apoptosis has some morphological characteristics, which include cell shrinkage, membrane blebbing, chromatin condensation, formation of apoptotic bodies and internu- cleosomal DNA fragmentation (9). Caspase-3 activation is a significant hallmark of apoptosis following ischemic and hemorrhagic brain insults $(5,27)$. An increment in the numbers of TUNEL-positive and caspase-3-positive cells in the hippocampus represents acceleration of apoptotic cell death $(5,28)$. In oxygen-glucose deprivation conditions, pre-administration of dexmedetomidine reduced neuronal death and cleaves caspase-3 expression (21). Furthermore, Eser et al (25) reported that dexmedetomidine treatment decreased the number of TUNEL-positive cells in the hippocampus following transient global cerebral ischemia/reperfusion injury in rats. Dexmedetomidine also inhibited isoflurane-induced caspase-3 expression (26). In the present study, the numbers of caspase-3-positive and TUNEL-positive cells in the hippocampus were increased following cerebral ischemia, and dexmedetomidine treatment suppressed these numbers in the ischemic gerbils. Thus, the results of the present study revealed that dexmedetomidine had a suppressive effect on ischemia-induced apoptosis in the hippocampus of gerbils. 

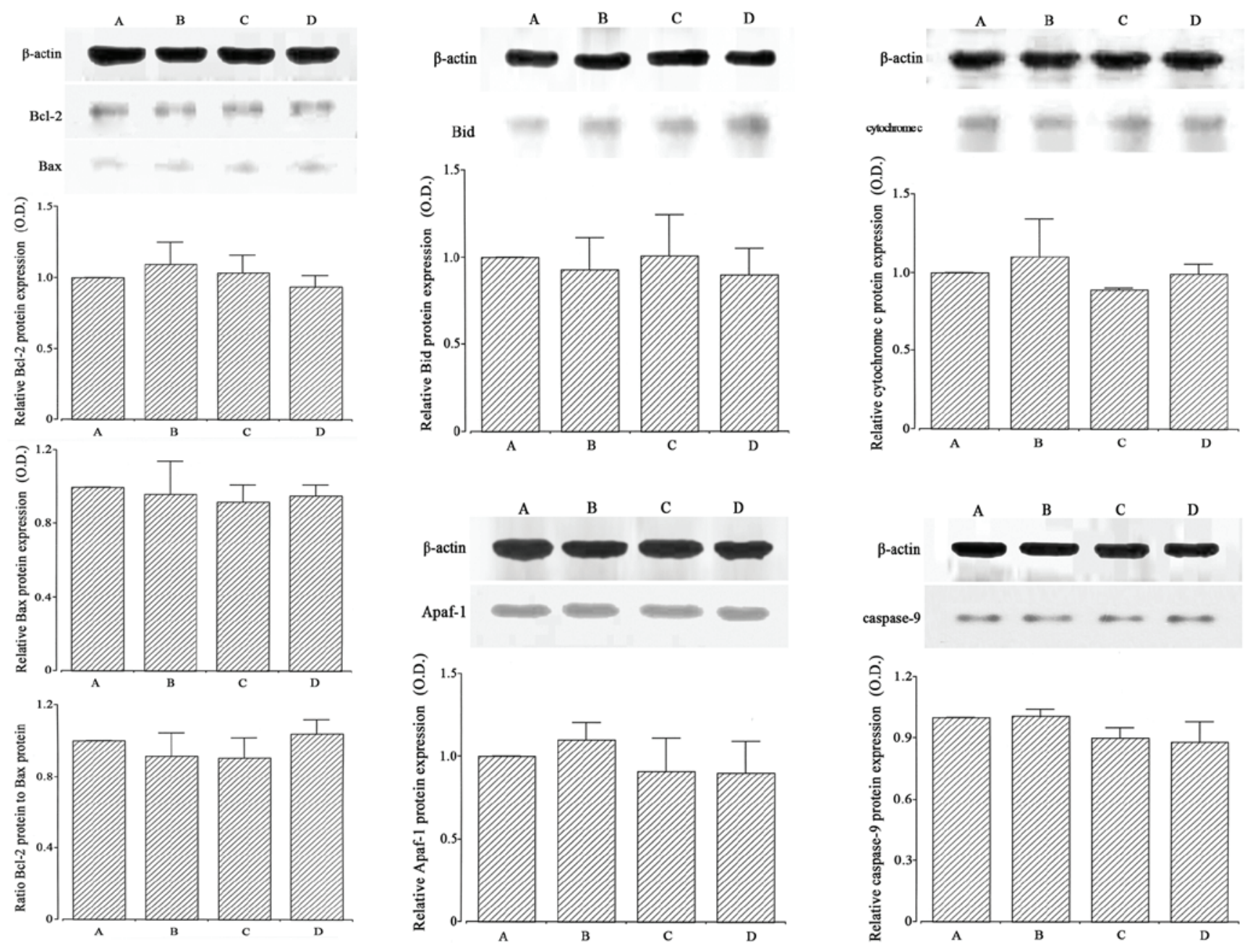

Figure 6. Effects of dexmedetomidine on the expression of apoptotic proteins under normal conditions. Actin was used as an internal control (43 kDa). (A) Sham-operated, (B) Sham-operated and $0.1 \mu \mathrm{g} / \mathrm{kg}$ dexmedetomidine-treated, (C) Sham-operated and $1 \mu \mathrm{g} / \mathrm{kg}$ dexmedetomidine-treated and (D) Sham-operated and $10 \mu \mathrm{g} / \mathrm{kg}$ dexmedetomidine-treated groups. The results are expressed as the mean \pm standard error of the mean. Bcl-2, B-cell lymphoma 2; Bax, Bcl-2-associated X protein; O.D, optical density; Apaf-1, apoptotic protease activating factor-1.

Bax and Bcl-2 are two separate members of a gene family that is important in the regulation of apoptosis $(7,8)$. Although they share partial nucleotide sequence homology, their individual products possess opposing functions. Bcl-2 is functionally characterized as an apoptosis-suppressing factor, whereas Bax is considered as an apoptosis-promoting factor $(8,10)$. Furthermore, several inhibitors of Bax suppress neuronal apoptosis (29). In the study by Engelhard et al (30), induction of cerebral ischemia/reperfusion injury, the relative protein concentration of Bax was increased, in contrast, dexmedetomidine treatment upregulated $\mathrm{Bcl}-2$ expression. The balance and the location of anti-apoptotic proteins versus pro-apoptotic proteins are closely associated with cell death or survival following focal cerebral ischemia (31). Moreover, the ratio of Bax to Bcl-2 is an important factor that determines whether cells undergo apoptosis (32), and ischemic brain injury disrupts this ratio (33). In addition, Bid is a cytosolic membrane protein of the Bcl-2 family that is pro-apoptotic. It is translocated from the cytoplasm into the mitochondria when the cell receives a death signal (34). Moreover, it is also known to be a critical mediator for inducing ischemic cell death in neurons (35). In the present study, the expression of
Bcl-2 in the hippocampus was decreased following cerebral ischemia; in contrast, the expression of Bax and Bid in the hippocampus was increased. In addition, dexmedetomidine treatment enhanced Bcl-2 expression and suppressed Bax and Bid expression in the ischemic gerbils. Thus, the results of the present study indicate that the anti-apoptotic effect of dexmedetomidine was achieved through upregulation of Bcl-2 with downregulation of Bax and Bid in the hippocampus of ischemic gerbils.

Furthermore, Bcl-2 can inhibit apoptosis by preventing the release of cytochrome $c$ from the mitochondria, and Bax appears as the dominant pro-apoptotic protein involved in cytochrome $c$ release $(13,14)$. Cytochrome $c$ release that is induced by calcium in neurons during ischemia involves mitochondrial outer membrane rupture, and can be blocked by inhibitors of the mitochondrial permeability transition (13). Thus, such inhibitors have demonstrated efficacy in animal models of ischemia (29). Continuous mitochondrial fission and fusion are involved in the apoptotic neuronal cell death in the ischemic penumbra following transient middle cerebral artery occlusion in mice (36). In the present study, cytochrome $c$ expression in the hippocampus was increased 
following cerebral ischemia, and dexmedetomidine treatment suppressed cytochrome $c$ expression in the hippocampus of ischemic gerbils. Thus, in the present study, dexmedetomidine had a suppressive effect on ischemia-induced cytochrome $c$ expression in the hippocampus of gerbils.

Once cytochrome $c$ is released, it activates the cytosolic protein Apaf-1 as well as procaspase-3 and procaspase-9, and together with ATP, they from an apoptosome (15). Cytochrome $c$-initiated activation of Apaf- 1 is a crucial step in the mitochondrial-signaling pathway for the activation of death-executing caspases in apoptosis. Since this signaling pathway has been implicated in the pathophysiology of various neurological disorders including ischemic brain injury, molecular targeting of the Apaf-1-caspase-9 signaling pathway may be a possible neuroprotective strategy for enhancing the endogenous threshold for caspase activation and prevent neuronal loss in stroke and related disorders (37). Apaf-1 expression was demonstrated to be increased by permanent focal ischemia in rats, and downregulation of Apaf-1 could have a potential clinical value for the treatment of stroke (38). In the present study, caspase- 9 and Apaf-1 expression in the hippocampus was decreased, and dexmedetomidine treatment inhibited caspase- 9 and Apaf- 1 expression in the hippocampus of ischemic gerbils. These observations indicate that the anti-apoptotic effect of dexmedetomidine was also achieved through downregulation of the Apaf-1-caspase-9 signaling pathway in the hippocampus of ischemic gerbils.

In the present study, dexmedetomidine suppressed the expression of apoptosis-related molecules under ischemic conditions, resulting in short-term memory improvement. In the previous study, dexmedetomidine did not induce apoptosis in the brachial plexus of rats (39). The present study also revealed that dexmedetomidine did not exert any effects on the apoptosis-related molecules under the normal (Sham operation) conditions. Therefore, the $\alpha_{2}$-adrenoceptor agonist dexmedetomidine is suggested to be capable of overcoming cerebral ischemia-induced neuronal apoptotic cell death, which thus facilitates memory recovery following ischemic cerebral injury.

\section{Acknowledgements}

The present study was supported by the Basic Science Research Program through the National Research Foundation of Korea founded by the Ministry of Education, Science and Technology (grant no. 2011-0013878).

\section{References}

1. González RG: Imaging-guided acute ischemic stroke therapy: From 'time is brain' to 'physiology is brain'. AJNR Am J Neuroradiol 27: 728-735, 2006.

2. McLean C and Ferriero D: Mechanisms of hypoxic-ischemic injury in the term infant. Semin Perinatol 28: 425-432, 2004

3. Pereira LO, Arteni NS, Petersen RC, da Rocha AP, Achaval M and Netto CA: Effects of daily environmental enrichment on memory deficits and brain injury following neonatal hypoxia-ischemia in the rat. Neurobiol Learn Mem 87: 101-108, 2007.

4. Ko IG, Shin MS, Kim BK, Kim SE, Sung YH, Kim TS, Shin MC, Cho HJ, Kim SC, Kim SH, et al: Tadalafil improves short-term memory by suppressing ischemia-induced apoptosis of hippocampal neuronal cells in gerbils. Pharmacol Biochem Behav 91: 629-635, 2009.
5. Suh HJ, So SM, Na YG, Ko IG, Kim SE, Sung YS, Shin MS, Kim CJ, Cho YS and Kim KH: Neuroprotective effects of tamsulosin on intracerebral hemorrhage. Neural Regen Res 6: 2505-2510, 2011.

6. Mattson MP, Duan W, Pedersen WA and Culmsee C: Neurodegenerative disorders and ischemic brain diseases. Apoptosis 6: 69-81, 2001

7. Thompson CB: Apoptosis in the pathogenesis and treatment of disease. Science 267: 1456-1462, 1995.

8. Hwang L, Choi IY, Kim SE, Ko IG, Shin MS, Kim CJ, Kim SH, Jin JJ, Chung JY and Yi JW: Dexmedetomidine ameliorates intracerebral hemorrhage-induced memory impairment by inhibiting apoptosis and enhancing brain-derived neurotrophic factor expression in the rat hippocampus. Int J Mol Med 31: 1047-1056, 2013

9. Li Y, Chopp M, Jiang N, Zhang ZG and Zaloga C: Induction of DNA fragmentation after 10 to 120 minutes of focal cerebral ischemia in rats. Stroke 26: 1252-1257; discussion 1257-1258, 1995.

10. Reed CJ: Apoptosis and cancer: Strategies for integrating programmed cell death. Semin Hematol 37 (4 Suppl 7): 9-16, 2000.

11. Benchoua A, Guégan C, Couriaud C, Hosseini H, Sampaïo N, Morin D and Onténiente B: Specific caspase pathways are activated in the two stages of cerebral infarction. J Neurosci 15: 7127-7134, 2001

12. Kato $\mathrm{H}$ and Kogure K: Biochemical and molecular characteristics of the brain with developing cerebral infarction. Cell Mol Neurobiol 19: 93-108, 1999.

13. Zamzami N, Susin SA, Marchetti P,Hirsch T, Gómez-Monterrey I, Castedo M and Kroemer G: Mitochondrial control of nuclear apoptosis. J Exp Med 183: 1533-1544, 1996.

14. Narita M, Shimizu S, Ito T, Chittenden T, Lutz RJ, Matsuda H and Tsujimoto Y: Bax interacts with the permeability transition pore to induce permeability transition and cytochrome $c$ release in isolated mitochondria. Proc Natl Acad Sci USA 95: 14681-14686, 1998.

15. Love S: Apoptosis and brain ischaemia. Prog Neuropsychopharmacol Biol Psychiatry 27: 267-282, 2003.

16. Venn RM and Grounds RM: Comparison between dexmedetomidine and propofol for sedation in the intensive care unit: Patient and clinician perceptions. Br J Anaesth 87: 684-690, 2001.

17. Gertler R, Brown HC, Mitchell DH and Silvius EN: Dexmedetomidine: A novel sedative-analgesic agent. Proc (Bayl Univ Med Cent) 14: 13-21, 2001.

18. Laudenbach V, Mantz J, Lagercrantz H, Desmonts JM, Evrard P and Gressens P: Effects of alpha(2)-agonist adrenoceptor agonists on perinatal excitotoxic brain injury: Comparison of clonidine and dexmedetomidine. Anesthesiology 96: 134-141, 2002.

19. Ma D, Hossain M, Rajakumaraswamy N, Arshad M, Sanders RD, Franks NP and Maze M: Dexmedetomidine produces its neuroprotective effect via the alpha 2A-adrenoceptor subtype. Eur J Pharmacol 502: 87-97, 2004.

20. Zhang Y and Kimelberg HK: Neuroprotection by alpha 2-adrenergic agonists in cerebral ischemia. Curr Neuropharmacol 3: 317-323, 2005.

21. Dahmani S, Rouelle D, Gressens P and Mantz J: Effects of dexmedetomidine on hippocampal focal adhesion kinase tyrosine phosphorylation in physiologic and ischemic conditions. Anesthesiology 103: 969-977, 2005.

22. Rajakumaraswamy N, Ma D, Hossain M, Sanders RD, Franks NP and Maze M: Neuroprotective interaction produced by xenon and dexmedetomidine on in vitro and in vivo neuronal injury models. Neurosci Lett 409: 128-133, 2006.

23. Kim SE, Ko IG, Park CY, Shin MS, Kim CJ and Jee YS: Treadmill and wheel exercise alleviate lipopolysaccharide-induced short-term memory impairment by enhancing neuronal maturation in rats. Mol Med Rep 7: 31-36, 2013.

24. Jeon JW, Lee JI, Shin HP, Cha JM, Joo KR, Kim SH, Ko IG, Jin JJ, Kim SE and Kim CJ: Adenosine $\mathrm{A}_{2 \mathrm{~A}}$-receptor agonist polydeoxyribonucleotide promotes gastric ulcer healing in Mongolian gerbils. Anim Cells Sys 18: 399-406, 2014.

25. Eser O, Fidan H, Sahin O, Cosar M, Yaman M, Mollaoglu H, Songur A and Buyukbas S: The influence of dexmedetomidine on ischemic rat hippocampus. Brain Res 1218: 250-256, 2008.

26. Sanders RD, Sun P, Patel S, Li M, Maze M and Ma D: Dexmedetomidine provides cortical neuroprotection: Impact on anaesthetic-induced neuroapoptosis in the rat developing brain. Acta Anaesthesiol Scand 54: 710-716, 2010.

27. Choi JH, Kim TS, Park JK, Sim YJ, Kim K and Lee SJ: Short-term treadmill exercise preserves sensory-motor function through inhibiting apoptosis in the hippocampus of hypoxic ischemia injury rat pups. J Exerc Rehabil 9: 457-462, 2013. 
28. Kim M, Cho KH, Shin MS, Lee JM, Cho HS, Kim CJ, Shin DH and Yang HJ: Berberine prevents nigrostriatal dopaminergic neuronal loss and suppresses hippocampal apoptosis in mice with Parkinson's disease. Int J Mol Med 33: 870-878, 2014.

29. Jemmerson R, Dubinsky JM and Brustovetsky N: Cytochrome $c$ release from CNS mitochondria and potential for clinical intervention in apoptosis-mediated CNS diseases. Antioxid Redox Signal 7: 1158-1172, 2005.

30. Engelhard K, Werner C, Eberspächer E, Bachl M, Blobner M, Hildt E, Hutzler P and Kochs E: The effect of the alpha 2-agonist dexmedetomidine and the N-methyl-D-aspartate antagonist $\mathrm{S}(+)$-ketamine on the expression of apoptosis-regulating proteins after incomplete cerebral ischemia and reperfusion in rats. Anesth Analg 96: 524-531, 2003.

31. Hu XL, Olsson T, Johansson IM, Brännström T and Wester P Dynamic changes of the anti- and pro-apoptotic proteins Bcl-w, Bcl-2 and Bax with Smac/Diablo mitochondrial release after photothrombotic ring stroke in rats. Eur J Neurosci 20: 1177-1188, 2004

32. Chung JW, Seo JH, Baek SB, Kim CJ and Kim TW: Treadmill exercise inhibits hippocampal apoptosis through enhancing $\mathrm{N}$-methyl-D-aspartate receptor expression in the MK-801-induced schizophrenic mice. J Exerc Rehabil 10: 218-224, 2014.

33. Dave KR, Bhattacharya SK, Saul I, DeFazio RA, Dezfulian C, Lin HW, Raval AP and Perez-Pinzon MA: Activation of protein kinase $C$ delta following cerebral ischemia leads to release of cytochrome $c$ from the mitochondria via bad pathway. PLoS One 6: e22057, 2011.
34. Sugawara T, Fujimura M, Noshita N, Kim GW, Saito A,Hayashi T, Narasimhan P, Maier CM and Chan PH: Neuronal death/survival signaling pathways in cerebral ischemia. NeuroRx 1: 17-25, 2004.

35. Broughton BR, Reutens DC and Sobey CG: Apoptotic mechanisms after cerebral ischemia. Stroke 40: e331-e339, 2009.

36. Liu W, Tian F, Kurata T, Morimoto N and Abe K: Dynamic changes of mitochondrial fusion and fission proteins after transient cerebral ischemia in mice. J Neurosci Res 90: 1183-1189, 2012.

37. Cao G, Xiao M, Sun F, Xiao X, Pei W, Li J, Graham SH, Simon RP and Chen J: Cloning of a novel Apaf-1-interacting protein: A potent suppressor of apoptosis and ischemic neuronal cell death. J Neurosci 24: 6189-6201, 2004.

38. Xu XH, Hua YN, Zhang HL, Wu JC, Miao YZ, Han R, Gu ZL and Qin ZH: Greater stress protein expression enhanced by combined prostaglandin A1 and lithium in a rat model of focal ischemia. Acta Pharmacol Sin 28: 1097-1104, 2007.

39. Han JH, Kim DO, Yi JW, Park SW, Kang WJ, Choi YK, Kim SH, Ko IG, Jin JJ, Kim SE and Kim CJ: Dexmedetomidine, $\alpha_{2}$-adrenoceptor agonist, does not induce apoptosis in the brachial plexus of rats. Anim Cells Sys 18: 407-415, 2014. 